Editorial

\title{
Uncorrected refractive error in the Australian National Eye Health Survey
}

\author{
Paul N. Baird $\mathrm{PhD}^{1}$ and J ost B. Jonas $\mathrm{MD}^{2}$
}

1) Department of Surgery| Ophthalmology, Faculty of Medicine, Dentistry and Health Sciences, The University of Melbourne

2) Department of Ophthalmology, Medical Faculty Mannheim of the Ruprecht-KarlsUniversity of Heidelberg, Mannheim, Germany

Correspondence: Prof. Paul Baird, PhD, Department of Surgery| Ophthalmology, Faculty of Medicine, Dentistry and Health Sciences, The University of Melbourne; Royal Victorian Eye and Ear Hospital, 32 Gisborne Street, East Melbourne, Victoria 3000 Australia

E: pbaird@unimelb.edu.au

Funding sources / Financial disclosure: NHMRC Senior Research Fellowship \#1138585 (PNB)

Conflict of interest: The authors have no conflict of interest with the current study.

This is the author manuscript accepted for publication and has undergone full peer review but has not been through the copyediting, typesetting, pagination and proofreading process, which may lead to differences between this version and the Version of Record. Please cite this article as doi: $10.1111 /$ ceo.13698

This article is protected by copyright. All rights reserved. 
The 56th World Health Assembly passed a resolution in 2003 to eliminate avoidable blindness and urged member states to develop a national Vision 2020 plan. ${ }^{1}$ In Australia, this led to the establishment of the National Eye Health Framework that would work in combination with non- government organisations and the private sector to achieve these goals. ${ }^{2}$ As we move into 2020, we should ponder the question as to the progress towards this objective.

A recent meta-analysis from 2015 detailing the prevalence and causes of worldwide vision impairment and blindness reported that uncorrected or undercorrected refractive error continued to be the leading cause of moderate or severe vision impairment (MSV). ${ }^{3}$ It was estimated that 217 million individuals globally were affected by MSVI with 116 million of them being attributable to uncorrected or under-corrected refractive error. ${ }^{3}$ Similarly, 7.4 million of the 36 million individuals classified as blind on a global basis were also the result of uncorrected or under-corrected refractive error being only second to cataract as the most common cause of blindness. 3

In Australia, the results of the Australian National Eye Health Survey (NEHS) reported in 2017 that the main cause of vision impairment continued to be uncorrected refractive error corresponding to $61 \%$ of the total. ${ }^{4}$ Notably, while the overall prevalence of vision loss in Australia was reported at $6.6 \%$, there was a marked contrast in prevalence of vision loss between non-Indigenous Australians at $6.5 \%$ compared to Indigenous Australians at $11.2 \% .{ }^{4}$ The main contributing risk factors for vision loss in non-Indigenous Australians were increasing age (odds ratio [OR], 1.72 per decade) and not having had an eye 
examination within the past year (OR, 1.61). In Indigenous Australians these risk factors included older age ( $O R, 1.61$ per decade), remoteness (OR, 2.02), gender (OR, 0.60 for men), and diabetes in combination with never having had an eye examination (OR, 14.47). ${ }^{4}$ Their conclusions were that vision loss was more prevalent in Indigenous Australians compared to non-Indigenous Australians thereby indicating that improvements in eye healthcare in this group were required.

In the current issue of the journal, Keel and colleagues have extended their analysis to establish risk factors associated with severe uncorrected refractive error that may underpin the previously reported vision loss and blindness. $\mathbf{5}$ In the included paper, they examined 1738 Indigenous Australians aged 40 to 92 years and 3098 non-Indigenous Australians aged 50 to 98. They reported the prevalence of severe uncorrected refractive error in the NEHS at $11.0 \%$ in the non-Indigenous group and $14.5 \%$ in the Indigenous study group. 5 Severe uncorrected refractive error was defined as an improvement of $\geq 2$ lines on the logMAR chart in one or both eyes in participants with a presenting visual acuity of $<6 / 12$. Associated risk factors were older age (OR 3.59), habitation in outer regional areas (OR 1.78) and lack of an eye examination in the previous two years (OR 1.5) for the Indigenous group. In the non-Indigenous group, these risk factors were older age (OR 1.51), habitation in outer regional areas (OR 0.68 for inner regional) and male gender (OR 1.30). 5 The comparison of risk factors alerts us to several interesting findings involving demographics, age and modifiable risk factors. While we cannot stop natural ageing, we can and should be aiming to provide equitable access to services and resources whether 
individuals reside in a remote or inner-city location. Importantly, being a male non-Indigenous individual had an increased risk and begs the question of lack of take-up of provided services or some other factor. In Indigenous individuals, the lack of a recent eye examination and living in outer regional areas appear as the strongest risk factors.

Keel's study, as well as previous findings from the NEHS and other international studies from around the globe all report that under-correction of refractive error is the leading cause of MSVI and the second leading cause of blindness. It is clear that a regular eye examination in combination with the provision of glasses with best correction of the refractive error is the most effective, most economical and safest of all measures to minimize vision loss in the general population, both in Australia and worldwide.

With respect to Keel's study and to most previously related investigations, it should be considered that the terms "uncorrected and under-corrected refractive error" are a more precise description than the term "uncorrected refractive error". The latter terminology as defined by Keel et al and by other studies refers to the difference between presenting visual acuity and best corrected visual acuity rather than under-corrected visual acuity. The conclusions should therefore be considered of not only providing correcting glasses to the uncorrected population but also to those where there is suboptimal correction.

One should also consider that assessment of near vision should be included in vision impairment as a measure of under-corrected presbyopia. A prior study by the NEHS group indicated that overall weighted prevalence of presenting near 
vision was $21.6 \%(95 \% \mathrm{Cl}: 19.6,23.8)$ in non-Indigenous Australians and $34.7 \%$ (95\% Cl: $29.2,40.8)$ in Indigenous Australians. 6 Thus as an increasing part of our daily activities now takes place indoors this type of under-correction also poses as a considerable public health issue. Additionally, lower levels of visual acuity have shown a correlation with decreased cognitive function over a 10-year period and thus this is of importance in an increasingly ageing population. 7

The Keel study indicated that one third of non-Indigenous and half of Indigenous participants were able to exhibit four or more lines improvement with correction. The majority of these are likely individuals who present with some level of nuclear cataract. Confidence in this assertion arises from the reported prevalence of any cataract at $24 \%$ in non-Indigenous and $33 \%$ in Indigenous participants. $\mathbf{5}$ It would be interesting to undertake a longitudinal study as part of the NEHS to investigate the slow progression of nuclear cataracts over time in the older age group. This may lead to lentogenic mypopization and the need for distance glasses correction or change in existing correcting glasses. As discussed by the authors, this observation fits with those participants who have not had an ocular examination in the previous two years and who are at a higher risk of severe under-correction of their refractive error.

The Australian Government has invested large amounts of funding in the "Closing the Gap I nitiative" and improving eye health for I ndigenous Australians will receive $\$ 34$ million over the next 5 years. 8 The Keel study confirms previous investigations that under-corrected refractive error plays a leading role as cause for MSVI and blindness worldwide and extends this finding to the Australian 
Indigenous population. It also indicates that a number of Indigenous and nonIndigenous Australians show severe visual impairment and it is likely that the majority of them could be readily corrected with appropriate glasses.

So what should be done? Keel and colleagues have suggested that spherical correction of the refractive error (its spherical equivalent) is better than no correction. In particular, they pointed out that the cylindrical refractive error was usually relatively small. Another explanation may be that a correction of the spherical refractive error, leaving the (minor to moderate) cylindrical refractive error uncorrected, reduces the best visual acuity at the focus of the optical system, but may increase the depth of focus. It may be of importance if corrected visual acuity is relatively high and reading glasses are not available. While this maybe one approach, the best option would be the provision of a simple automatic refractometry allowing provision of the best correcting glasses to markedly improve vision for this population. The findings presented in the Keel study are not unique to Australia but also transculturally valid. Therefore, public health measures should continue to raise awareness of the importance of regular optometric examinations.

In conclusion, we need to assess the gaps that exist in service provision, the targeting and the take-up of optometric services particularly in outer and remote regions in elderly individuals in order to reduce levels of under-correction of refractive error. If this can be achieved, then we could make some rapid gains in eye health at a public health level that are sustainable beyond the current fiveyear funding period. 


\section{REFERENCES}

1. WHO Fact Sheet No 282. VISION 2020: The Right to Sight, the Global Initiative for the Elimination of Avoidable Blindness. Magnitude and causes of visual impairment-No cause for complacency. WHO: Geneva, 2004

2. Commonwealth of Australia. National Framework for Action to Promote Eye Health and Prevent Avoidable Blindness and Vision Loss. 2005; ISBN: 0642828342 Publications Approval Number: 3791

3. Flaxman SR, Bourne RRA, Resnikoff S, Ackland P, Braithwaite T, Cicinelli MV, Das A, J onas JB, Keeffe J, Kempen JH, Leasher J, Limburg H, Naidoo K, Pesudovs K, Silvester A, Stevens GA, Tahhan N, Wong TY, Taylor HR; Vision Loss Expert Group of the Global Burden of Disease Study. Global causes of blindness and distance vision impairment 1990-2020: a systematic review and meta-analysis. Lancet Glob Health. 2017; 5:e1221-e1234.

4. Foreman J, Xie J, Keel S, van Wijngaarden P, Sandhu SS, Ang GS, Fan Gaskin J, Crowston J, Bourne R, Taylor HR, Dirani M. The Prevalence and Causes of Vision Loss in Indigenous and Non-Indigenous Australians: The National Eye Health Survey. Ophthalmology. 2017 Dec; 124(12): 1743-1752.

5. Keel S, McGuinness MB, Foreman J, Scheetz J, Taylor HR, Dirani M. Prevalence, associations and characteristics of severe uncorrected refractive error in the Australian National Eye Health Survey. Clin Experiment Ophthalmol. 2019;1-10. https://doi.org/10.1111/ceo.13647.

6. Keel S, Foreman J , Xie J , Taylor HR, Dirani M. Prevalence and associations of presenting near-vision impairment in the Australian National Eye Health Survey. Eye (Lond). 2018; Mar; 32(3):506-514.

7. Elyashiv SM, Shabtai EL, Belkin M. Correlation between visual acuity and 
cognitive functions. Br J Ophthalmol. 2014; 98:129-132.

8. Commonwealth of Australia. Closing the Gap Report 2019 (c) 2019 ISBN 9781-925363-83-8 Closing the Gap Report 2019 (Print); ISBN 978-1-925363-84-5 Closing the Gap Report 2019 (online)

This article is protected by copyright. All rights reserved. 


\section{University Library}

\section{- M M N E R VA A gateway to Melbourne's research publications}

Minerva Access is the Institutional Repository of The University of Melbourne

Author/s:

Baird, PN;Jonas, JB

Title:

Uncorrected refractive error in the Australian National Eye Health Survey

Date:

2020-01-01

Citation:

Baird, P. N. \& Jonas, J. B. (2020). Uncorrected refractive error in the Australian National Eye Health Survey. CLINICAL AND EXPERIMENTAL OPHTHALMOLOGY, 48 (1), pp.9-11. https:// doi.org/10.1111/ceo.13698.

Persistent Link:

http://hdl.handle.net/11343/275219 